\title{
COMPARISON OF CLUSTER C PERSONALITY DISORDERS IN COUPLES WITH NORMAL DIVORCE
}

\author{
M. Jamali ${ }^{1, *}$ and M. Bayrami ${ }^{2}$ \\ ${ }^{1}$ MSc General Psychology, Islamic Azad University of Tabriz \\ ${ }^{2}$ Associate Professor and Dean of the Faculty of Education and Psychology, University of \\ Tabriz
}

Published online: 15 May 2016

\begin{abstract}
The main purpose of this study was to compare personality disorders in Cluster $\mathrm{C}$ with normal couples divorce. In this cross-sectional study.The study population consisted of men and women seeking divorce Urmia in 2010, which was referred to the offices of the two groups, men and women seeking divorce (33 males and 33 females) in normal men and women, (33 male, and 33 women) who were to survive, were studied. In fact, 66 students (33 males and 33 females) and the average number of couples (33 male and 33 female) were selected according to age and education. In this study, to collect non-probabilistic of divorce available for sampling were used. Also purposeful sampling was used to select individuals. To collect data from a pivotal clinical questionnaire was 3 million. For two-way analysis of variance was used to analyze the data. The results showed that the rate of cluster B personality disorder is more common in people divorce than people. Meanwhile, the findings showed that the personality disorder group $\mathrm{C}$, there is no significant difference between men and women.
\end{abstract}

Keywords: Personality Disorders; Cluster C; Divorce.

Author Correspondence, e-mail: authorsC@gmail.com

doi: http://dx.doi.org/10.4314/jfas.v8i3s.170 


\section{INTRODUCTION}

To sustain a living, many researchers, Love to see a powerful motivator, but on the other hand, according to Erickson (quoted from Bayrami 1378), the group of young people who have only coherent identity, and it can make sure they feel sincerely, And persons from the opposite sex to be successful. Aaron Tybk (quoted from the Tiber, 1990), F believes that the difficulty in understanding human relationships and substance abuse, Or in other words the difference in attitudes that lead to conflict and its consequences, Cultural differences in attitudes so that this difference has a significant share. Today's civilized society and industry specific consequences following that including it, Vacillation and weakness and loss of family foundations affection among its subjects. Since the family is considered the cornerstone of society, Charhandyshy must consolidate it and ultimately attempt to create, Emotional bonds within the family was to work, otherwise, Fzyanhay brings irreversible. Family smallest part of human social life and, in turn, it is the most important component, The important part, a very strong enemy called divorce, the lack of understanding and compromise, and so on. Matters of divorce, the major issues are important to human society is even religious communities, and if today there is the divorce rate was increased (Bayrami, 1378). Injury or family problems, a series of events or events that one or more or all of their family members or family generally imposed on the body and all family members are affected. Some of these problems and difficulties such as divorce of parents, Issues related to family communication, while others are due, Unexpected events such as illness, disability and accidents are present (Street, 1382). Divorce, separation of women to men in the dictionary, releases the shackles of marriage and marital freedom. In common sense, the sense of separation is also in mind. Without any doubt, divorce is the most difficult social phenomena. Because of this phenomenon among Pvshydhtryn and even unspeakable and complex aspects of human life. This phenomenon has a number of sides and sides all aspects of human society: The first is a psychological phenomenon, because in psychological adjustment not only two people, but the children, their close relatives and puts effect. Second, an economic phenomenon, That leads to the breakdown of the family as an economic unit and elimination of human mental balance, Causing devastating effects in economic life also provides them Divorce may be psychological disorders, On the other hand it can be a mental abnormality caused or exacerbate them. Many studies show that among the reasons that have led to divorce, Psychological aspect is very important. While one of the couples treated with psychological disorders, Is most likely to be affected was another wife. Vulnerability to mental disorders 
occurs especially in the early years of marriage, and almost half of divorces occur in the first year of life MyᄀPyvndnd 9. On the other hand marital problems among psychiatric patients is very common, And did not deny, but marital problems and secret My $\neg$ Mand. Personality disorder is an important source of marital problems that can create discord and cause marital problems, and can be identified with a variety of personality. "A personality disorder, Stability pattern of inner experience and behavior and cultural expectations, significantly inconsistent, is pervasive and inflexible, Begins in adolescence or early adulthood, Stable over time and leads to distress or impairment "(quoted from Nikkhooi, 1383). Personality traits, sustainable patterns of perception, communication, thinking about the environment and are themselves in a wide range, Social and personal backgrounds appear. Only when personality traits inflexible and inconsistent, and caused considerable disorder and mental distress, they constitute personality disorders (Karimi, 1374). In fact, in three clusters of personality disorders sorted, the cluster C personality disorder, avoidant, dependent, obsessive-compulsive located, this cluster is examined in this study. Pervasive pattern of social inhibition among avoidant personality disorder, insufficency feelings and sensitive to, Negative evaluation, which started in early adulthood, defined as. People with avoidant personality disorder, academic or occupational activities that involve interpersonal contact are high, Because of fears of criticism, disapproval or rejection are avoided. People with avoidant personality disorder often associated with consciousness, Movements and statements of people who are associated with them, scrutinize. They may be frightened and anxious behavior makes a mockery and ridicule latest by others; which in turn raises their forms and uncertainties. Dependent personality disorder to be protected as well as the needs of learners and extreme submissiveness behavior, Dependence leads and fears of separation. The main feature of dependent personality disorder, pervasive and excessive need to be protected is, dependent behavior and fears of separation leads to submissiveness. This pattern began early adolescence and appearance becomes in a variety of fields. Acts of domination and dependence, to draw attention to the root are used and from the impression, without the help he can no longer function properly. On the other hand obsessive-compulsive personality disorder is a pervasive pattern of preoccupation with respect to law and order, Perfectionism and mental and interpersonal control at the expense of flexibility, Openness and efficiency can be defined. The main feature of obsessive-compulsive personality disorder, preoccupation with order, Perfectionism, and mental and interpersonal control, at the expense of flexibility, Openness and efficiency. This pattern started in early adulthood and appears in a variety of 
fields. These people are trying to rule through much attention to detail in vain, methods, Schedule gain a sense of control in such a way that the main purpose of the activity is lost. For example, the study found that the personality paranoid, schizoida ntisocial, obsessive compulsive Hystryanyk can, associated with marital problems (Sims, 1995). In this study, Friedman (1995) Personality disorder and major depression were the main causes of divorce. The Vkatlyn Bruce (1992), personality disorder and major depression to know the main causes of divorce, and that these relationships significant to consider (quoting Maghsoudlou, the Holy One, 1379). In a study the relationship between mental disorders such as substance abuse, and personality characteristics have been confirmed by divorce (Goldman, 2000). The research literature points to the conclusion that, among those with personality disorders Hystryanyk, Antisocial and Obsessive highest incidence of divorce is seen (MacKinnon, 1971). In this manifestation (1379) studied under the influence of psychological factors, The incidence of divorce referred to intervene in crises, National Social Isfahan Province; The results showed that the proportion of wives who are one of a kind, Psychiatric disorders were studied spouses of $7 / 37 \%$, respectively. The frequency of psychiatric disorders in this group of patients, $13 \%$ in personality disorders, major depression $2 / 29 \%$, delusions of jealousy 6/24\% 3\% schizophrenia, depression, bipolar 6/4\% obsessive-compulsive 6/4\%; Psychiatric disorders unclassified $5 \%$. In one study it was shown that $5 / 38 \%$ of those studied, MMPI test results are abnormal personality, That both sexes $40 \%$ of women and $72 / 35 \%$ of the cases, MMPI test were abnormal at least one scale (Zahiraddini and Khdayyfr, 1380). This research Sugar and colleagues (1385) under review, Personality traits, social skills Attachment styles and demographic characteristics as predictions, Successfully defeat laundering in relation to adultery and divorce applicant couples of Ahvaz, The results confirmed the hypothesis and showed that, Failure and success in the marital relationship could be over, The variables of personality traits, social skills, Attachment styles and demographic characteristics predicted (quoting Goldsmith and Neshatdoost, 1386). In a study by Smith and vitality friend, (1386) as the main factors influencing the incidence of divorce has been Isfahan city, Injuries and problems that couples and their families, Before the divorce and then incur and factors affecting the incidence of divorce, Has been investigated. The results showed that the highest percentage of couples referred,

To divorce reduction centers $(7 / 66 \%)$ were referred by the judicial authorities and law enforcement, and about $33 \%$ of them have been referred to your representative, And suffer from a personality disorder. In a study (Nassiri et al., 1379), Determined to divorce as 
couples who check profile, Crisis intervention center welfare organization of Isfahan, Showed that couples wishing to divorce significant differences in features, Clinical characters and words can not do with each other, a significant difference from a pathological point of view, For couples wishing to divorce and especially the men and women Lack of clinical and pathological significance of the differences Between couples can show that differences in behavioral style couples, due to their relationship. Today, divorce is one of the most complex issues of this century that modern industrialized society.

Women entering the labor market and individual freedom Not only is it a problem linked and do not separate from the community, But most of the scholars is a multidimensional phenomenon divorce, Can be prevented from occurring by removing an agent (Asgari, 1380). It's crucial to have the right attitude to this problem, In addition to our knowledge and according to the statistics of divorce, has scant perception of the environment. As well as the increase of divorce in the past decade the stage, That society is faced with many problems, so that, In this period, the divorce rate has been increasing with the growth of cities and provinces of the country,And relevant officials and experts to examine social issues and solution is required. This study aimed to compare personality disorders couples, Divorce is depicted in comparison with ordinary people, since the conflict in marital relations is inevitable, Because of individual differences is the cause of conflict.Thus the need for the study and research of this issue seems undeniable.

\section{RESEARCH HYPOTHESES}

1. Between spouses and divorce due to their gender, there are differences in terms of avoidant personality.

2. Mtqazytlaq habits among couples according to their gender, there is a dependent personality.

3. Between divorced spouses and normal according to their gender, there is a difference of obsessive-compulsive personality.

\section{Way}

This descriptive study was causal-comparative. The population of this study included men and women were divorced, The divorce offices in Urmia in 1389 were referred to in the form of two groups, Group of men and women divorce (33 men and 33 women) and ordinary men and women (33 men and 33 women), Continued taking her own life, were studied. In fact, 66 patients (33 males and 33 females) and the normal number of couples (33 males and 33 
females), Depending on the age and education were selected. In this study, to collect the divorce of sampling,

Non-probabilistic sample was used and available for selection; in this way, in coordination with the Office of divorce in the city of Orumiyeh 3, of those who were willing to cooperate with researchers and divorce, The samples were selected. As well as normal couples, With respect to demographic characteristics such as age, Education, marriage and divorce matched with the group, were chosen for.

\section{RESEARCH TOOLS}

Millon Clinical Inventory 3 (MCMI-III): The questionnaire filled by million based on the theory of biological, psychosocial made. Among his short descriptive questionnaire included 175 responses Bly- is good, 14 the character and measures 10 clinical syndromes for adults 18 years and older is applicable. I. Sy.am. 3, one of the most widely used psychological tests, based on the model of psychopathology million (1969/1983) is made, And has been translated into several languages, Am.sy.am.y -3 -2 Am.sy.am.y is the revised version, F. In August 1994 meeting of the American Psychological Association introduced. Clinical models of personality in Am.sy.am.y -3 includes: (Schizoid (scale 1), Dvrygzyn (Scale A2), depression (scale B2), dependent (Measure 3), View (scale of 4), narcissistic (Scale 5), antisocial (scale A6), Sadistic (scale B6), OCD (level 7), Mnfygra (scale A8), injuries (scale B8), Injuries included severe personality (schizotypal (Measure S), borderline (Measure C) and paranoid (Measure P), Clinical syndrome (anxiety disorder (Measure A), Shbhjsmy (Measure H), Mania (scale N), dysthymia (Measure D), alcohol dependence (Measure B), Drug dependence (scale $\mathrm{T}$ ) and post-traumatic stress (scale R), More severe clinical symptoms (thought disorder (scale SS), Major depression (scale CC) delusional disorder (scale PP) are (Millon, 1385). Grieg has reported that about reliability Am.sy.am.y 3, there are five sets of data, In these studies, the test-retest interval of 5 days to 6 months. From 0/58 to 0/93 scales moderate correlations for personality disorders (depression) with an average of 0/78 is obtained. In the clinical syndrome scales, Moderate correlations of the range of 0/44 (PTSD) to 0/95 (MDD), with an average of 0/80 is obtained (quoted Millon, 1385). Mugahi eunuchs in the study, test-retest reliability coefficient of -2 Am.sy.am.y scales, with an interval of 7 to 10 days from the slopes 0/78 (display) to $87 / 0$ (delusional disorder) is obtained.

The mean internal consistency of the scale with a range of 69/0 (delusional disorder), 0/92 
(Border) is obtained with an average 0/84 (Khvajhmvg.hy, 1372) In this study, to analyze data in addition to descriptive statistical methods, Such as frequency and frequency for twoway analysis of variance was used to analyze hypothesis.

\section{FINDINGS}

Of the 132 participants, the youngest participant was 22 years, and the highest age of participants is 55 years. The age range for participants in the study, Ages 26, 29 and 35 years and up. Participants also study the level of high school (35\%), High school diploma, associate degree and bachelor's (3/23) and a bachelor's degree and higher (4/18 percent). It is worth noting that Bh $\neg \mathrm{Lt}$ condition of participation in the study was at least a degree cycle; it was not the illiterate people to use. Hypothesis 1: between the divorced spouses and normal, according to the levels of sex (woman or man) there is a difference of avoidant personality Nzrakhtlal.

Table 1. Measures of central tendency and dispersion avoidance personality disorder based on gender and marital status

\begin{tabular}{|c|c|c|c|c|c|}
\hline Ordinary & & orce & & Sex & Variable \\
\hline SD & $\mathrm{X}$ & $\mathrm{SD}$ & $X$ & & Avoidance \\
\hline $4 / 70$ & $6 / 28$ & $4 / 40$ & $8 / 1$ & Female & personality \\
\hline $3 / 59$ & $5 / 28$ & $6 / 36$ & $8 / 45$ & Man & disorder \\
\hline
\end{tabular}

Contents Table 1 shows the mean scores of divorce, the variable avoidance personality disorder compared to other higher level. In other words, the avoidance personality disorder ordinary people, they are better than divorce.

Table 2. Two-way analysis of variance interaction between marital status and gender in avoidance personality disorder

\begin{tabular}{llllll}
\hline $\mathbf{P}$ & $\mathbf{F}$ & MS & DF & SS & \\
\hline $0 / 007$ & $7 / 68$ & $180 / 085$ & 1 & $180 / 085$ & Situation (divorce / Normal) \\
$0 / 752$ & $0 / 102$ & $2 / 405$ & 1 & $2 / 405$ & Sex \\
$0 / 422$ & $0 / 655$ & $15 / 408$ & 1 & $15 / 408$ & reaction \\
& & $23 / 575$ & 128 & $2735 / 12$ & Error variance \\
& & 132 & 8798 & Variance Category Overview \\
\hline
\end{tabular}


Table of Contents Table 2 shows the effect of marital status (divorce and normal), Brakhtlal avoidance character, is statistically significant, $\mathrm{F}$ is calculated as $(7 / 68)$ at $0 / 01>\mathrm{P}$ meaningful and according to the average of the two groups, Divorce $(1.8,45.8)$ and normal $(6 / 28,5 / 28)$ can be concluded, Normal people divorce than those of signs, Avoidance personality disorder are more. So part of the research hypothesis is confirmed. The effect of gender on avoidance personality disorder, No statistically significant, F is calculated as (0/1) at 0/05> P not significant. Hence it can be concluded that between men and women, in terms of avoidance personality disorder There is no significant difference, So part of the research hypothesis can not be confirmed. On the one hand the effect of the interaction of gender and marital status (divorce and normal) the avoidance personality disorder is not significant, $\mathrm{F}$ is calculated as $(0 / 6)$ at $0 / 05>\mathrm{P}$ not significant. So we can conclude that the avoidance personality disorder, In between the applicant and divorce due to their gender, statistically not significant. The interactive hypothesis is not confirmed.

Hypothesis 2: between the divorced spouses and normal operating according to gender (being a woman or a man), There is a difference of Nzrakhtlal dependent personality.

Table 3. Measures of central tendency and dispersion dependent personality disorder based on gender and marital status

\begin{tabular}{|c|c|c|c|c|c|}
\hline Ordinary & & orce & & Sex & Variable \\
\hline $\mathrm{SD}$ & $\mathrm{X}$ & SD & $X$ & & Dependent \\
\hline $3 / 66$ & $10 / 56$ & $3 / 65$ & $11 / 15$ & Female & personality \\
\hline $3 / 59$ & $8 / 85$ & $4 / 74$ & $10 / 20$ & Man & disorder \\
\hline
\end{tabular}

Table 3 shows that the mean divorce, in variable dependent personality disorder compared to other higher level. In other words, the dependent personality disorder ordinary people, they are better than divorce.

Table 4. Analysis of variance Two-way interaction between gender and marital status of dependent personality disorder

\begin{tabular}{llllll}
\hline $\mathbf{P}$ & $\mathbf{F}$ & MS & DF & SS & \\
\hline $0 / 172$ & $1 / 88$ & $29 / 005$ & 1 & $29 / 005$ & Situation (divorce / Normal) \\
$0 / 0752$ & $3 / 132$ & $49 / 405$ & 1 & $49 / 405$ & Sex \\
$0 / 720$ & $0 / 117$ & $1 / 86$ & 1 & $1 / 86$ & reaction \\
\hline
\end{tabular}


In Table 4 shows that the effect of marital status (divorce and normal), brakhtlal dependent personality, Darnyst statistically significant, $\mathrm{F}$ is calculated as $(1 / 88)$ at $0 / 01>\mathrm{P}$ not significant, and it can be concluded that divorce and ordinary people, the dependent personality disorder There is no significant difference. The effect of gender on the dependent personality disorder, No statistically significant, $\mathrm{F}$ is calculated as $(3 / 31)$ at $0 / 05>\mathrm{P}$ not significant. Hence it can be concluded that between men and women, the dependent personality disorder there is no significant difference. On the one hand the effect of the interaction of gender and marital status (divorce and normal), dependent personality disorder is not significant, $\mathrm{F}$ is calculated as $(0 / 11)$ at $0 / 05>\mathrm{P}$ not significant. So we can conclude that the dependent personality disorder, In between the applicant and divorce due to their gender, is no different. The interactive hypothesis is not confirmed.

Hypothesis 3: between the divorced spouses and normal operating according to gender (being a woman or a man),

There character of OCD.

Table 5. Measures of central tendency and dispersion compulsive personality disorder based on gender and marital status

\begin{tabular}{|c|c|c|c|c|c|}
\hline Ordinary & & orce & & Sex & Variable \\
\hline SD & $X$ & SD & $\mathrm{X}$ & & Obsessive- \\
\hline $3 / 18$ & $16 / 87$ & $3 / 015$ & $17 / 50$ & Female & compulsive \\
\hline $3 / 79$ & $16 / 80$ & $2 / 94$ & $16 / 90$ & Man & $\begin{array}{l}\text { personality } \\
\text { disorder }\end{array}$ \\
\hline
\end{tabular}

Table of Contents Table 5 shows that the mean divorce, the variable obsessive personality disorder compared to other higher level. In other words, the obsessive-compulsive personality disorder ordinary people, they are better than divorce. 
Table 6. Analysis of variance Two-way interaction between gender and marital status in compulsive personality disorder

\begin{tabular}{llllll}
\hline $\mathbf{P}$ & $\mathbf{F}$ & MS & DF & SS & \\
\hline $0 / 652$ & $0 / 203$ & $2 / 144$ & 1 & $2 / 144$ & Situation (divorce / Normal) \\
$0 / 49$ & $0 / 457$ & $4 / 78$ & 1 & $4 / 78$ & Sex \\
$0 / 51$ & $0 / 385$ & $4 / 04$ & 1 & $4 / 04$ & reaction \\
& & $10 / 60$ & 128 & $1224 / 15$ & Error variance \\
& & 132 & 36255 & Variance Category Overview \\
\hline
\end{tabular}

Table of Contents Table 6 shows the effect of marital status (divorce and normal), Brakhtlal obsessive character, Darnyst statistically significant, $\mathrm{F}$ is calculated as $(0 / 02)$ at $0 / 01>\mathrm{P}$ not significant, and it can be concluded that the divorce between the people and the ordinary, the symptoms of obsessive-compulsive personality disorder There is no significant difference. The effect of gender on obsessive-compulsive personality disorder, statistically not significant, $\mathrm{F}$ is calculated as $(0 / 045)$ at $0 / 05>\mathrm{P}$ not significant. Hence it can be concluded that between men and women, The symptoms of obsessive-compulsive personality disorder There is no significant difference.On the one hand the effect of the interaction of gender and marital status (divorce and normal), The symptoms of obsessive-compulsive personality disorder is not significant, $\mathrm{F}$ is calculated as $(0 / 38)$ at $0 / 05>\mathrm{P}$ not significant. So we can conclude that the obsessive-compulsive personality disorder, In between the applicant and divorce due to their gender, is no different. The interactive hypothesis is not confirmed.

\section{DISCUSSION AND CONCLUSION}

The results showed that ordinary men and women divorce, Clinically significant differences in the pattern together with cluster C personality; In other words F obtained for the gender factor in clinical Algv $\neg$ Hay above, F can be expected at 5\% level of error is larger. This finding is consistent with research results (McKinnon, 1971; Bruce and Kathleen, 1992; beach and O'Leary, 1993) consonants. The cluster C personality disorders that are related to divorce, which can be based on the features available in each of the couples, from the emergence of problems in the family had hoped for. Cluster $\mathrm{C}$ personality traits of the pessimism, low selfesteem, Tend to be unnecessarily worried and sad, lifeless and negative behavior and personality traits of self-harm, Devotion and allowed the abuse to others, Relying on others to gain confidence and acceptance of guilt, And the neck is getting them because of their 
deliberate self-denial Avoidance characters with features such as the fear of being humiliated in interpersonal relationships, To refrain from social contact, resulting in isolation and away from people, It is clear that it can be problematic in relationships between couples. Because people with avoidant disorder than being criticized, or preoccupation with rejection in social situations, obviously threshold may be lower. Even with a small amount of disapproval or criticism, May be severely hurt. Because they fear that any attention from others probably will be rejected or humiliated, shy, quiet, Controlled, and the so-called "invisible" are. They expect anything to say, others call it a "mistake" to think and, therefore, may never tell anything. These subtle cues to react so severely, As if the references are indicated Asthza'ya sarcasm. Despite the desire to participate actively in social life, I have always been afraid of welfare dependent on others. People with avoidant personality disorder refrain from participating in new interpersonal situations, And poor self-esteem because they enjoy the feeling of inadequacy. In fact, the reason may be criticized, with a blush or cry react very Mztrbnd. Others see them as people shy, timid, isolated describe. Major problems related to the social and occupational dysfunction occur. Poor self-esteem, and extreme sensitivity to rejection, Interpersonal relationships are limited to the relationship; these factors cause the divorce rate, People with avoidant personality disorder increase (McKinnon, 1971). People with dependent personality disorder, such as the cessation of support or approval of fear, Often in opposition to other people, especially those who are dependent problems. These people feel that they alone are incapable, so prefer to think things, It is wrong to agree with this, the risk of losing support from those, you expect them to guidance, are excluded. They where appropriate, to the people who need their support and love, Fear of upsetting them, not anger. People with this disorder is possible to earn the love and support of others, To carry out extreme measures, so that also volunteer for unpleasant tasks, Especially if such behavior attention that they need to be followed (Criterion 5). These people will give up what others are, Even if these demands are unreasonable. They need to establish an important link often leads Vtyrh balanced relations. They may be unusual in such a bad devote themselves to others or verbal behaviors, Physical or sexual endure. They are important to people, "attach" to avoid being alone, Even if not involved in this relationship or to be disinterested. When a sincere relationship is interrupted (Beach and O'Leary, 1993). On the one hand people with obsessive-compulsive personality disorder are extremely accurate and tendency to repeat, and their attention to detail is extraordinary, and to find possible errors, repeatedly checking their work. They are unaware of the fact that other people because of the delays and problems of 
their behavior, Experiencing discomfort. For example, such people when the list of things you need to do, Lost rather than by spending a little time to recall and rewrite it to, And then to complete their tasks, they spend too much time finding it. They do not adjust your schedule correctly, and put the most important things for the last minute. Perfectionism imposition of measures on their high level of performance, Cause dysfunction and great confusion in the people. They may not be as much involved in all the details of a project are completed, that the plan did not complete. So these people expect that their partner, the more these things do not happen, because the other side and the relationship adversely affected; So the divorce rate also increased in this group (Kaplan and Sadvk, 2000). Therefore, based on research findings using clinical scale, Millon 3 in Justice and Family Courts to, Understanding personality is suggested. The advantage of this test counseling, Young maiden could be useful. On the one hand this research, the main limitation of this study was limited, Taking advantage of the available sample, the generalizability of the sample of the problem. Other limitations of this study, the large number of questions in the questionnaire that a total of 11 characters and 3 clinical pattern of severe damage, the character can be measured and the results were unfortunately in some cases Byshtrazmvdnyha; do not answer the questionnaire completely. On the other hand find divorce (male and female), 66 people who have the least education guidance, and in the most critical moments of life are willing to answer 175 questions, the main limitation of this study.

\section{REFERENCES}

[1] Bayrami, d. (1378). Family and its pathology. Tabriz publication of Aydin.

[2] Tiber, b. (1372). Children of divorce. T. translations of Civilization (1990).

[3] Khwaja Mugahi, N. (1372). Preliminary preparation Persian form Millon clinical questionnaire 2 million in Tehran. Master Thesis. (Unpublished).

[4] Tehran Psychiatric Institute. Goldsmith, acidity and vivacious friend, h. (1386). Evaluation of risk factors for divorce Falavarjan city. Master's thesis, University of Isfahan.

[5] Saroukhani, B. (1376). Research in knowing the reality of divorce and its agents Publishing and Printing Institute of Tehran University.

[6] Zahiraddini, AR. Khdayyfr, Fatima. (1380). Personality profiles. Referring to Tehran Family Court divorce. Quarterly grace, No. 25, Springer 1382. 
[7] Asgari, h. (1380). The role of mental health in marriage, divorce. Tehran: the conversation.

[8] Millon, d. (1385). Help Am.sy.am.y. Translator Ali Akbar Sharifi.

[9] Nasir Hamid Pour .mlk, Mkhtar.zary, Azam. (1379), Check profile is determined to divorce couples in crisis welfare organization of Isfahan. Congress of the causes and consequences of divorce.

[10]Beach, S.R., \& OLeary, R.D. (1993). Dysphoria and marital discord: Are dysphoria individuals at risk for marital maladjustment? Journal of Marital and family Therapy, 19,355-368.

[11]Boisvert, J.M., \& Ladouceur, R. (1995). Perception of marital problems and their prevention by Quebec young adults. Journal of Genetic psychology, 159, 33-41.

[12] Grill, E. \& Crispin, A. (2002). Health related lifestyles and personality traits in fathers of children of minor age. Gesundheitswesen. 64(1):19-24.

[13] Kaplan, H \& Sadoc, B. (2000). Synopsis of psychiatry. 9 th ed, Lippincott Williams and Wilkins. 44-5,800, 181-2.

[14] Mac Kinnon Roger, A. (1971). The psychiatric interview in clinical practice. W.B.Saunder company.115-117.

[15] Magai, .C. (1999). Personality change in adulthood; loci of change and the role of interpersonal process. Int-journal-A ging-hum-Der, 49 (4); 339-52.

[16] Millon, T. (2004). Personality disorders in modern life. John wiley \& sons, InC. 616. 85, $81 \mathrm{dc} 22$.

[17] Sims, A. (1995). Symptoms in the mind. Saunders company ltd. 257.259.

[18] Goldman, N. (2000). The association between health; related behaviours and the risk of divorce in the USA. Journal, Biosoc-sci.Jan; 32(1); 63-88.

[19] Womle, D. L. (1969). Foundations for marriage and family relations. NewYork: the Macmillan Company. - www.nocr-ag.ir.

\section{How to cite this article:}

Jamali $\mathrm{M}$ and Bayrami M. Comparison of cluster c personality disorders in couples with normal divorce. J. Fundam. Appl. Sci., 2016, 8(3S), 116-128. 